\title{
Concentration Effects of Silver Ions on lonic Conductivities of Molten Silver Halides
}

\author{
S. Tahara ${ }^{1,2}$, S. Ohno ${ }^{1}$, T. Okada ${ }^{3}$, Y. Kawakita ${ }^{4}$, and S. Takeda ${ }^{2}$ \\ ${ }^{1}$ Faculty of Pharmacy, Niigata University of Pharmacy and Applied Life Sciences, 265-1 Higashijima, Akiha-ku, Niigata \\ 956-8603, Japan \\ ${ }^{2}$ Department of Physics, Faculty of Sciences, Kyushu University, 6-10-1 Hakozaki, Higashi-ku, Fukuoka 812-8581, Japan \\ ${ }^{3}$ Niigata College of Technology, Kamishin'ei-cho, Nishi-ku, Niigata 950-2076, Japan \\ ${ }^{4}$ Japan Atomic Energy Agency, 2-4 Shirakata Shirane, Tokai-mura, Naka-gun, Ibaraki 319-1195, Japan
}

\begin{abstract}
Ionic conductivities of molten $(\mathrm{RbX})_{c}(\mathrm{AgX})_{1-c}(\mathrm{X}=\mathrm{Cl}$ and I) mixtures were measured to clarify the concentration effects of silver ions on ionic conductivities of molten silver halides. It is found that the addition of $\mathrm{RbX}$ to molten $\mathrm{AgX}$ rapidly reduces the ionic conductivity with $0 \leq c \leq 0.4$. It suggests that strong $\mathrm{Ag}-\mathrm{Ag}$ correlation is necessary to fast conduction of $\mathrm{Ag}$ ions in molten state. The absolute values of ionic conductivity for $(\mathrm{RbCl})_{c}(\mathrm{AgCl})_{1-c}$ are larger than those for $(\mathrm{RbI})_{c}(\mathrm{AgI})_{1-c}$ mixtures at all compositions. These differences might relate to difference of diffusion constant between $\mathrm{Cl}^{-}$and $\mathrm{I}^{-}$and difference of effective charge carried by an ion between molten $\mathrm{AgCl}$ and $\mathrm{AgI}$.
\end{abstract}

\section{Introduction}

Ionic conductivities, $\sigma$, of silver halides at solid and molten phases have been reported by many earlier works [1-11]. It is well known that $\sigma$ of superionic $\alpha$-AgI (high temperature solid phase of $\mathrm{AgI})$ is as large as that of molten salts, while $\sigma$ of crystal $\mathrm{AgBr}$ and $\mathrm{AgCl}$ under the atmospheric pressure are small even at high temperature $[10,11]$. Above the melting point, these silver halides show larger $\sigma$ than typical alkali halides [12]. Taking into account of the fact that $\mathrm{Ag}$ diffusion constants are more than twice as large as those of anions, fast diffusion of $\mathrm{Ag}$ ions even in molten phase causes high ionic conductivity [13-15]. Such a feature is very interesting, because Ag is heavy compared with alkali metals.

In our previous papers on structure of molten silver halides by high-energy x-ray diffraction, neutron diffraction and structural modelling by Reverse Monte Calro modelling [16-18], revealed that Ag distribution of molten AgI has large fluctuations where one-dimensional streams consisting of several Ag ions are formed. These results correspond to Ag-Ag partial pair distribution functions (pdf). The first peak of $\mathrm{Ag}-\mathrm{Ag}$ pdf of molten AgI shows penetration into the first coordination shell of Ag-I pdf, and a similar penetration is also reported by results of ab-initio molecular dynamics (MD) simulation [19]. It might suggest collective motions of Ag ions. On the other hand, $\mathrm{Ag}$ distribution of molten $\mathrm{AgCl}$ shows relatively a uniform-like feature [16-17]. However, it is still quite different from cation distribution of molten alkali halides in an extremely flat structure of the $\mathrm{Ag}-\mathrm{Ag}$ pdf [20]. An empirical MD simulation using the polarizable ion model based on Vashishta-Rahman potential reasonably reproduced the flat structure of AgAg pdf [13]. This structure-less of Ag-Ag pdf implies that correlations between $\mathrm{Ag}$ ions in molten $\mathrm{AgCl}$ might be weak like gas. The differences in Ag distribution between $\mathrm{AgI}$ and $\mathrm{AgCl}$ originate from effective charge carried by an ion and covalency of bonding between $\mathrm{Ag}$ and halogens. Much drastic changes of structure and transport properties are expected by varying $\mathrm{Ag}$ concentration. It is consider that $\mathrm{Ag}$ concentration variation is virtually possible by mixing Ag halides with alkali halides.

In this study, ionic conductivity of molten $(\mathrm{RbI})_{c}(\mathrm{AgI})_{1-c}$ and $(\mathrm{RbCl})_{c}(\mathrm{AgCl})_{1-c}$ mixtures which have eutectic concentration at $c=0.3$ and 0.4 [21-23], respectively, were measured. The $(\mathrm{RbI})_{c}(\mathrm{AgI})_{1-c}$ mixtures has stoichiometric compound $\operatorname{RbAg}_{4} I_{5}$ which shows the superionic phase even at room temperature [23-27], and its structure factor at molten phase has the largest scale of medium-range order in the molten $(\mathrm{RbI})_{c}(\mathrm{AgI})_{1-c}$ system [28]. We have two motivations in this study. First, whether dose the weakening of the strong $\mathrm{Ag}-\mathrm{Ag}$ correlation of molten AgI with decreasing Ag concentration affect ionic transport, or not? Second, are there differences between molten $(\mathrm{RbI})_{c}(\mathrm{AgI})_{1-c}$ and $(\mathrm{RbCl})_{c}(\mathrm{AgCl})_{1-c}$ mixtures according to the difference in $\mathrm{Ag}$ distribution between $\mathrm{AgI}$ and $\mathrm{AgCl}$ ? 


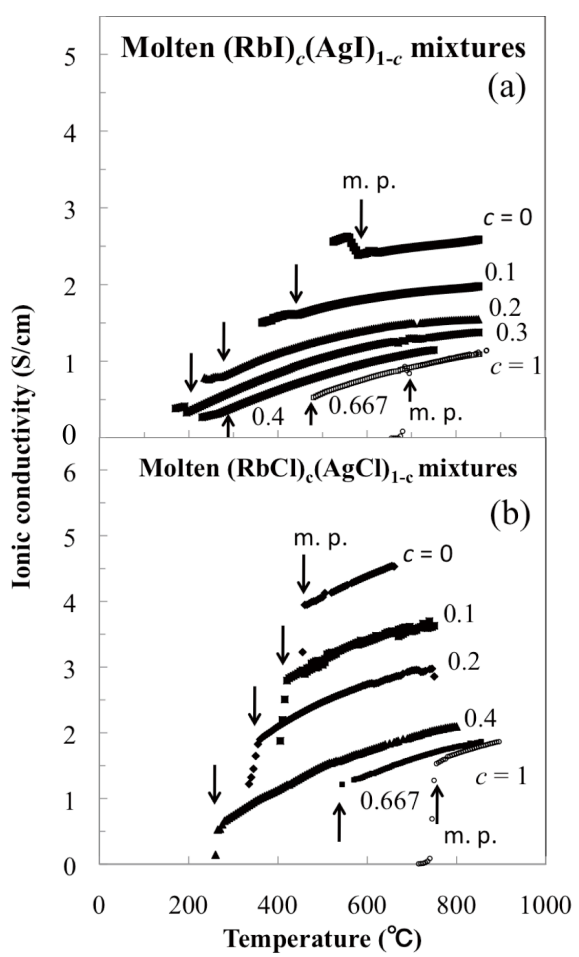

Fig. 1. Temperature dependences of ionic conductivity, $\sigma$, of molten (a) $(\mathrm{RbI})_{c}(\mathrm{AgI})_{1-c}$ and (b) $(\mathrm{RbCl})_{c}(\mathrm{AgCl})_{1-c}$ mixtures, respectively. Arrows exhibit melting points of these materials reported by thermodynamic investigations [21-23].

\section{Experimental procedure}

Samples of $(\mathrm{RbI})_{c}(\mathrm{AgI})_{1-c}(c=0,0.1,0.2,0.3,0.4,0.667$, 1) and $(\mathrm{RbCl})_{c}(\mathrm{AgCl})_{1-c}(c=0,0.1,0.2,0.4,0.667,1)$ mixtures were prepared by mixing powder materials of $\mathrm{AgI}$ and $\mathrm{RbI}$, or $\mathrm{AgCl}$ and $\mathrm{RbCl}$ in sealed quartz tube. Ionic conductivity measurements were performed by four-probes method using 3532-80 Chemical Impedance Meter (HIOKI E. E. Corporation) under a cooling process. A sample was put into quartz cell with $4 \mathrm{~mm}$ inner diameter where four small tapered holes are located with each $28 \mathrm{~mm}$ interval to insert carbon electrodes [29]. The carbon electrodes were fastened by nickel bands to prevent a leak of liquid sample. Each nickel band has a lead wire made of molybdenum to connect each electrode to 3532-80 Chemical Impedance Meter (HIOKI E. E. Corporation). Current was supplied to outside two electrodes, and voltage was measured at inside two electrodes. Cell constant was determined by using a standard aqueous solution of potassium chloride (76.5829 $\mathrm{g}-\mathrm{KCl} / \mathrm{kg}-\mathrm{H}_{2} \mathrm{O}$ ). The measurements were carried out under an argon atmosphere to prevent oxidation of molybdenum wires and vaporization of samples. Bubbles forming in a liquid sample during the measurements were removed as possible as we can by stirring it with a silica rod. The temperature was measured by using four chromel-alumel thermocouples immediately above the electrodes.

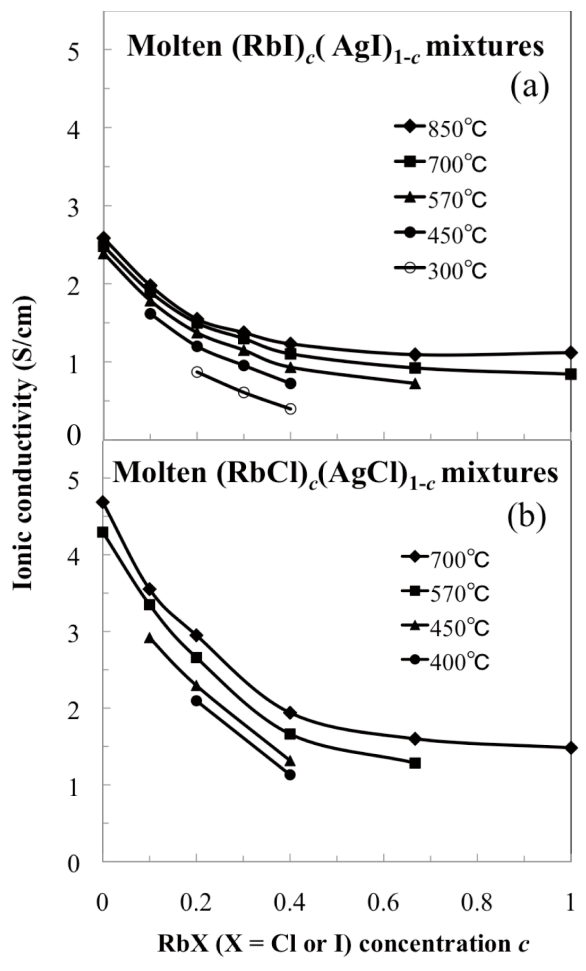

Fig. 2. Concentration dependence of ionic conductivity of molten (a) $(\mathrm{RbI})_{c}(\mathrm{AgI})_{1-c}$ and (b) $(\mathrm{RbI})_{c}(\mathrm{AgI})_{1-c}$ mixtures, respectively.

\section{Experimental results}

Figure 1 shows temperature dependences of $\sigma$ of molten (a) $(\mathrm{RbI})_{c}(\mathrm{AgI})_{1-c}$ and (b) $(\mathrm{RbCl})_{c}(\mathrm{AgCl})_{1-c}$ mixtures, respectively. We confirmed that the present ionic conductivities of molten $\mathrm{AgCl}, \mathrm{AgI}, \mathrm{RbCl}$ and $\mathrm{RbI}$ are in good agreement with those of earlier works [1-9, 30-31]. The increase of $\sigma$ of $\mathrm{AgI}$ at a phase transition from molten phase to the superionic $\alpha$-phase, is also reported by earlier works $[3-5,7]$. This increase of $\sigma$ relates to higher Ag conductivities in the superionic phase than those in molten phase at immediately around $T_{\mathrm{m}}$. From experimental and theoretical studies on a self-diffusion constant of $\mathrm{Ag}, D_{\mathrm{Ag}}$, of $\mathrm{AgI}$ beyond the transition point from $\alpha$-phase to molten phase, $D_{\mathrm{Ag}}$ in molten phase shows smaller value than that in superionic phase at around $T_{\mathrm{m}}$ [32-34]. The addition of $\mathrm{RbI}$ into molten AgI reduces $\sigma$ in the $\mathrm{RbI}$ concentration region less than 0.667 . The $\sigma$ of molten $(\mathrm{RbI})_{0.667}(\mathrm{AgI})_{0.333}$ described by open squares in figure 1(a) follows the same line of $\sigma$ of molten RbI described by open circles. Temperature coefficients of ionic conductivity, $\mathrm{d} \sigma / \mathrm{d} T$, are positive at all compositions of molten $(\mathrm{RbI})_{c}(\mathrm{AgI})_{1-c}$. The slope of $\sigma$ becomes gradually large with increasing RbI concentration. Focusing on near the eutectic composition, the slope varies with temperatures. The $\mathrm{d} \sigma / \mathrm{dT}$ of molten $(\mathrm{RbI})_{0.3}(\mathrm{AgI})_{0.7}$ is comparatively large at a low temperature and becomes small in a high-temperature region. 


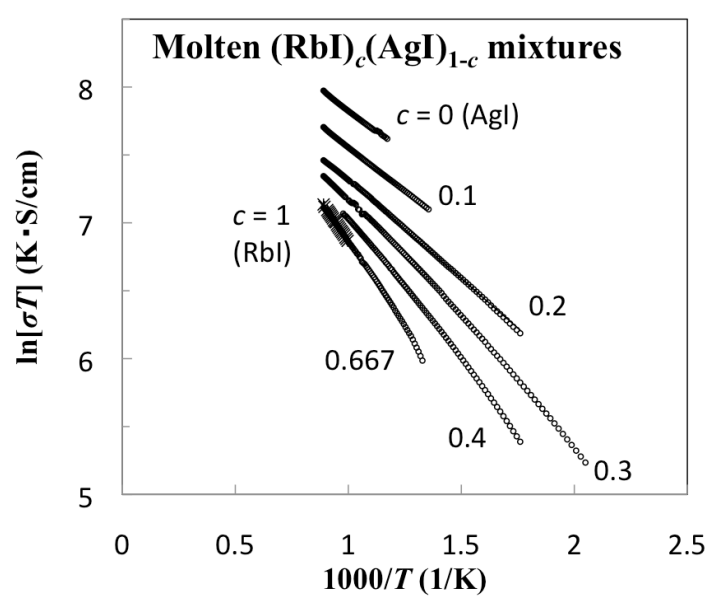

Fig. 3. Arrhenius plot of molten $(\mathrm{RbI})_{c}(\mathrm{AgI})_{1-c}$ mixtures.

The $\sigma$ of RbI-AgI mixtures below $T_{\mathrm{m}}$ might receive some influence of $\mathrm{Ag}$ conduction of $\alpha-\mathrm{RbAg}_{4} \mathrm{I}_{5}$ and $\alpha$ AgI. $\sigma$ of molten $(\mathrm{RbCl})_{c}(\mathrm{AgCl})_{1-c}$ shows similar temperature and concentration dependence as molten $(\mathrm{RbI})_{c}(\mathrm{AgI})_{1-c}$ except of a little higher conductivity of $\mathrm{AgCl}$ and rapidly decrease of $\sigma$ by solidification. Although a gradual increase of the slope by adding $\mathrm{RbCl}$ is not observed, the ratio of temperature coefficient to the $|\sigma|$ of molten $\mathrm{AgCl}$ is still smaller than that of molten $\mathrm{RbCl}$.

The concentration dependence of $\sigma$ of molten $(\mathrm{RbI})_{c}(\mathrm{AgI})_{1-c}$ and $(\mathrm{RbCl})_{c}(\mathrm{AgCl})_{1-c}$ mixtures are shown in Figs. 2(a) and 2(b), respectively. The $\sigma$ rapidly decreases with increasing concentration of $\operatorname{RbX}$ from $c=$ 0 to 0.4 , and then the $\sigma$ becomes almost constant at $0.4 \leq$ $c \leq 1$. These features are reported for molten KI-AgI, $\mathrm{KCl}-\mathrm{AgCl}$ systems, and so on [6]. The decrease of $\sigma$ with increasing concentration of $\mathrm{AgX}$, becomes more rapid as temperature decrease for molten $(\mathrm{RbI})_{c}(\mathrm{AgI})_{1-c}$, which is associated with small temperature dependence of $\sigma$ for molten AgI.

\section{Discussion}

The ionic conductivity is generally written by an Arrhenius expression

$\sigma T=A \exp \left(-E_{\mathrm{a}} / k_{\mathrm{B}} T\right)$

where $E_{\mathrm{a}}, A$, and $k_{\mathrm{B}}$ are the activation energy, the preexponential factor, and the Boltzmann constant, respectively [35-37]. In general, $E_{\mathrm{a}}$ is estimated by fitting a linear function to the Arrhenius plot $(\ln [\sigma T]$ vs. $1 / T)$. The Arrhenius plot of molten $(\mathrm{RbI})_{c}(\mathrm{AgI})_{1-c}$ mixtures is shown in figure 3 .

Figure 4 shows the concentration dependence of activation energy, $E_{\mathrm{a}}$, which is estimated by fitting a linear function to Arrhenius plot within the measured temperature region of each composition. The estimated $E_{\mathrm{a}}$ of molten $\mathrm{AgI}, \mathrm{AgCl}, \mathrm{RbI}$, and $\mathrm{RbCl}$ are 0.107, 0.114,

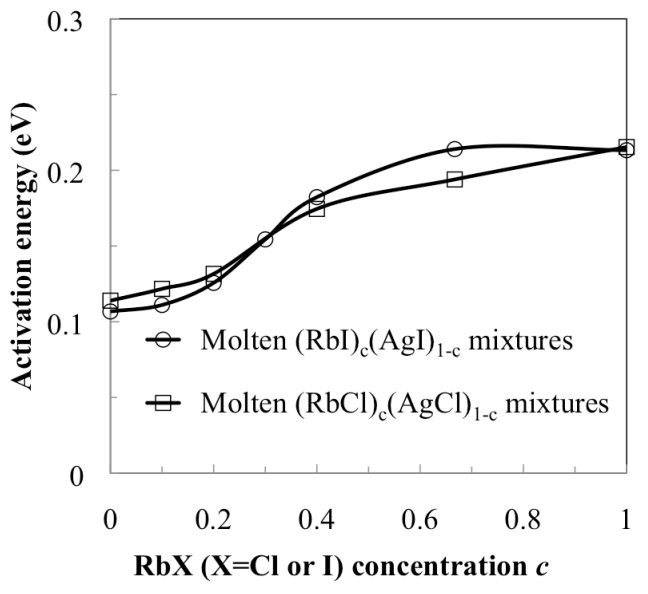

Fig. 4. Concentration dependence of activation energy for molten $(\mathrm{RbI})_{c}(\mathrm{AgI})_{1-c}$ and $(\mathrm{RbI})_{c}(\mathrm{AgI})_{1-c}$ mixtures obtained by fitting a linear function to the Arrhenius plot.

0.213 , and $0.215 \mathrm{eV}$, respectively. $E_{\mathrm{a}}$ of molten $\mathrm{AgX}$ are smaller than that of molten $\mathrm{RbX}$, which is consistent with the fact that the diffusion constant of $\mathrm{Ag}$ ions in molten $\mathrm{AgX}$ is higher than that of $\mathrm{Rb}$ in molten $\operatorname{RbX}[13,15,38]$. The $E_{\mathrm{a}}$ increases in the concentration region from $c=0.2$ to 0.4 where the melting point exhibits minimum. The $E_{\mathrm{a}}$ of molten AgI is slightly small compared with that of molten $\mathrm{AgCl}$. It is in good agreement with earlier work [8].

To compare the ionic transport properties between $(\mathrm{RbI})_{c}(\mathrm{AgI})_{1-c}$ and $(\mathrm{RbCl})_{c}(\mathrm{AgCl})_{1-c}$ precisely, the conductance per 1 mole-cubic which includes 1 mole molecules, $\sigma_{\text {mol }}$, was deduced to normalize by carrier density. $\sigma_{\mathrm{mol}}$ was estimated by

$\sigma_{\text {mol }}=\sigma \cdot(S / L)=\sigma \cdot V^{1 / 3}=\sigma \cdot\left(N_{\mathrm{A}} / \rho\right)^{1 / 3}$

where $V$ is the molar volume of materials. $L$ and $S$ are the side length of the 1 mole-cubic $\left(L=V^{1 / 3}\right)$ and the side area of the cubic $\left(S=L^{2}=V^{2 / 3}\right)$, respectively. $N_{\mathrm{A}}$ and $\rho$ are the Avogadro constant and the number density of molecules, respectively. Estimated $\sigma_{\text {mol }}$ for molten $(\mathrm{RbX})_{c}(\mathrm{AgX})_{1-c}$ mixtures at $750^{\circ} \mathrm{C}$ are shown in the figure 5. $\rho$ of molten $(\mathrm{RbX})_{c}(\mathrm{AgX})_{1-c}(c=0.1 \sim 0.667)$ mixtures was estimated from linear combination of molar volume between $\mathrm{AgX}$ and $\mathrm{RbX}$ [12].

The $\sigma_{\text {mol }}$ for molten $(\mathrm{RbI})_{c}(\mathrm{AgI})_{1-c}$ mixtures decreases rapidly with increasing $\mathrm{RbI}$ with $0 \leq c \leq 0.4$, and then settles to be almost constant with $0.4 \leq c \leq 1$. Taking into account of the fast collective migrations of $\mathrm{Ag}$ in molten $\mathrm{AgI}$, the collective motion of Ag rapidly decreases with increasing $\mathrm{RbI}$ concentration. Since such collective dynamics is ruled by the second power of the number density or higher order of the power, the rapid decrease of $\sigma_{\text {mol }}$ by adding RbI supports reasonably this dynamical model suggested from the static structural model. On the other hand, it is surprising that the concentration dependence for molten $(\mathrm{RbCl})_{c}(\mathrm{AgCl})_{1-c}$ shows a similar tendency with that for molten $(\mathrm{RbI})_{c}(\mathrm{AgI})_{1-c}$. It suggests that the diffusion of $\mathrm{Ag}$ ions in molten $\mathrm{AgCl}$ is also 


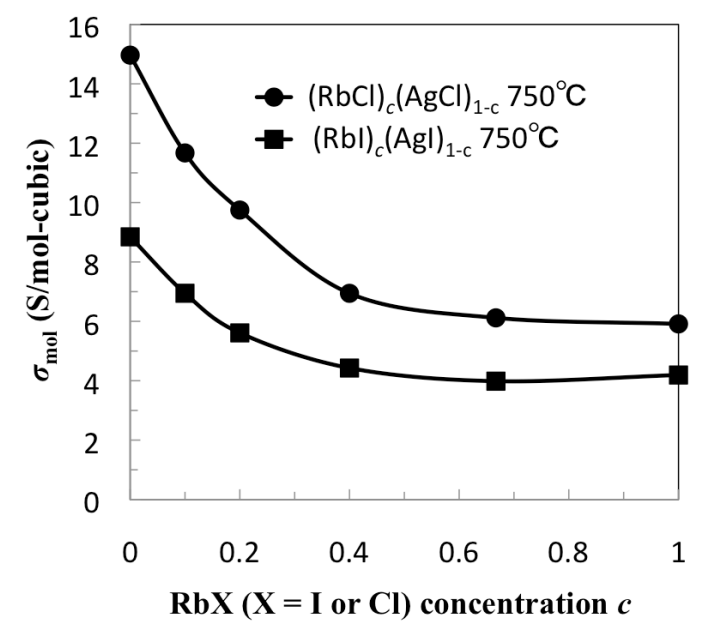

Fig. 5. Concentration dependence of $\sigma_{\mathrm{mol}}$ for molten $(\mathrm{RbX})_{c}(\mathrm{AgX})_{1-c}\left(\mathrm{X}=\mathrm{Cl}\right.$ or I) mixtures. $\sigma_{\mathrm{mol}}$ was estimated by equation (2) in the text.

regulated by many-body effect, inspite of flat and therefore weak correlations of $\mathrm{Ag}-\mathrm{Ag}$ partial pdf.

The absolute values of $\sigma_{\text {mol }}$ for molten $(\mathrm{RbCl})_{c}(\mathrm{AgCl})_{1-c}$ mixtures are higher than that for molten $(\mathrm{RbI})_{c}(\mathrm{AgI})_{1-c}$ mixtures at all compositions. $\sigma_{m o l}^{R b C l} / \sigma_{m o l}^{R b l}$ is 1.41 . Taking into account of fully ionic properties for $\mathrm{RbCl}$ and $\mathrm{RbI}$ and almost the same activation energies of $\sigma \mathrm{of} \mathrm{RbCl}$ and $\mathrm{RbI}$, the difference in $\sigma_{\mathrm{mol}}$ between molten $\mathrm{RbCl}$ and molten $\mathrm{RbI}$ may originate from the difference in diffusion constant between $\mathrm{Cl}^{-}$and $\mathrm{I}^{-}$ions. In fact MD predicts that the diffusion of $\mathrm{Cl}^{-}$ion in molten $\mathrm{RbCl}$ is much higher than that of $\mathrm{I}^{-}$ion in molten $\mathrm{RbI}\left(5.2 \times 10^{-5} \mathrm{~cm}^{2} / \mathrm{s}^{-5}\right.$ for $\mathrm{Cl}^{-}$ and $3.5 \times 10^{-5} \mathrm{~cm}^{2} / \mathrm{s}$ for $\mathrm{I}^{-}$) [38]. In Ag-rich concentration region, one can recognize an additional increase of $\sigma_{\mathrm{mol}}$ for molten $(\mathrm{RbCl})_{c}(\mathrm{AgCl})_{1-c}$ system. This may be attributed by difference in an effective charge carried by an ion between $\mathrm{AgCl}$ and $\mathrm{AgI}$. MD simulations predict the effective charges as 0.68 and 0.58 for molten $\mathrm{AgCl}$ and $\mathrm{AgI}$, respectively $[13,15]$. Many-body effect of molten $\mathrm{AgCl}$ might be related to a mechanism to reduce carrying charge from \pm 1 to \pm 0.68 . To avoid repulsive interactions by high density of $\mathrm{Ag}$ ions, carrying charge may be reduced through a covalent property of $\mathrm{Ag}-\mathrm{Cl}$ bonding character which may also cause polarizable property of $\mathrm{Cl}$ ions. Structural investigation of molten $(\mathrm{RbCl})_{c}(\mathrm{AgCl})_{1-c}$ and $(\mathrm{RbI})_{c}(\mathrm{AgI})_{1-c}$ mixtures, especially reduction of Ag-Ag partial correlations is indispensable to complete full discussion on transport properties in relation with unusual flat $\mathrm{Ag}-\mathrm{Ag}$ pdf of molten $\mathrm{AgCl}$ and anomalous Ag migration in molten AgI. We have already measured the structure of molten $(\mathrm{RbI})_{c}(\mathrm{AgI})_{1-c}$ mixtures [28] and we plan to measure the structure of molten $(\mathrm{RbCl})_{c}(\mathrm{AgCl})_{1-c}$ mixtures. We will discuss the relation between transport properties and the partial structures in a near future.

\section{Conclusion}

The $\sigma$ for molten $(\operatorname{RbX})_{c}(\mathrm{AgX})_{1-c}(\mathrm{X}=\mathrm{Cl}$ and $\mathrm{I})$ mixtures were measured as a function of temperature and concentration. The addition of $\mathrm{RbI}$ into molten $\mathrm{AgI}$ reduces $\sigma$ in the $\mathrm{RbI}$ concentration region less than 0.667 . This tendency suggests that the weakening of strong Ag$\mathrm{Ag}$ correlation of molten $\mathrm{AgI}$ affects ionic transport with $0 \leq c \leq 0.4$. It is interesting that similar tendency of concentration dependence was also seen for $(\mathrm{RbCl})_{c}(\mathrm{AgCl})_{1-c}$ mixtures. It suggests that the diffusion of $\mathrm{Ag}$ ions in molten $\mathrm{AgCl}$ is also regulated by manybody effect, inspite of weak Ag-Ag partial correlations. The concentration dependence of $\sigma_{\mathrm{mol}}$ which was normalized by carrier density for molten $(\mathrm{RbCl})_{c}(\mathrm{AgCl})_{1-c}$ was larger than that of $(\mathrm{RbI})_{c}(\mathrm{AgI})_{1-c}$ at all compositions. One origin of differences of $\sigma_{\text {mol }}$ between $(\mathrm{RbCl})_{c}(\mathrm{AgCl})_{1-c}$ and $(\mathrm{RbI})_{c}(\mathrm{AgI})_{1-c}$ would be differences of diffusion constants between $\mathrm{Cl}^{-}$and $\mathrm{I}^{-}$ions. In addition, differences of an effective charge carried by an $\mathrm{Ag}$ ion in molten $\mathrm{AgCl}$ and $\mathrm{AgI}$ also may contribute to the differences of $\sigma_{\text {mol }}$ between $(\mathrm{RbCl})_{c}(\mathrm{AgCl})_{1-c}$ and $(\mathrm{RbI})_{c}(\mathrm{AgI})_{1-c}$.

\section{Acknowledgement}

The authors thank to the students (Mr. Y. Yamamoto, Ms. M. Kondo, Mr. Y. Seno, and Mr. K. Musha) of the laboratory of Physics in Niigata University of Pharmacy and Applied Life Sciences for supports of the experiment.

\section{References}

1. H. Bloom and E. Heymann, Proc. R. Soc. Lond. A11 392 (1947)

2. M. C. Bell and S. N. Flengas, J. Electrochemical soc. 111575 (1964)

3. A. Kvist and A. M. Josefson Z. Naturforsch. 23a 625 (1968)

4. H. G. Damle and S. S. Katti Indian, J. Chem. 16A 679 (1978)

5. H. G. Damle and S. S. Katti Indian, J. Chem. 19A 896 (1980)

6. H. P. Boßmann, A. Hildebrandt, and J. Richter, Z. Naturforsch. 41a 1129 (1986)

7. A. Wojakowska, E. Kundys, J. Josiak, J. Materials science 312425 (1996)

8. K. Ishida, S. Ohno, T. Okada, J. Non-Crystaline solids, 250-252 488 (1999)

9. A. Chandra, A. Spangenberg, and J. Maier, J. Electroceramics 347 (1999)

10. K. Shahi, and J. B. Wagner Jr., J. Phys. and Chem. of Solids 43713 (1982)

11. M. E. V. Hulle, W. M.-V. D. Vorst, Physica status solidi (a) 40 K173 (2004)

12. G. J. Janz, Molten salts handbook (Academic Press in New York, NY 1967)

13. J. Trullàs, O. Alcaraz, L. E. González, and M. Silbert, J. Phys. Chem. B 107282 (2003)

14. V. Bitrian, J. Trullàs, J. Phys. Chem. B 1107490 (2006)

15. V. Bitrian, J. Trullàs, J. Phys. Chem. B 1121718 (2008) 
16. S. Tahara, H. Fujii, Y. Kawakita, S. Kohara, Y. Yokota, and S. Takeda, J. Non-cryst. Solids 353 1994 (2007)

17. Y. Kawakita, S. Tahara, H. Fujii, S. Kohara, and S. Takeda, J. Phys. :Condens. Matter 19335201 (2007)

18. H. Ueno, S. Tahara, Y. Kawakita, S. Kohara, and S. Takeda, Neuclear Instruments and Methods in Physics Research A 600322 (2009)

19. F. Shimojo, T. Inoue, M. Aniya, T. Sugahara, and Y. Miyata, J Phys. Soc. Jpn 75114602 (2006)

20. P. Ballone, G. Pastore, and M. P. Tosi, J. Phys. C : Solid State Phys. 17 L333 (1984)

21. R. Baboian and S. N. Flengas Canadian J. Chem. 45 813 (1967)

22. C. Sandonini and P. C. Aureggi Atti Accad. Nazl. Lincei, II 20588 (1911)

23. J. N. Bradley and P. D. Greene: Transactions of the Faraday Society. 63424 (1967)

24. B. B. Owens and G. R. Argue: Science 157308 (1967)

25. S. Geller: Science 157310 (1967)

26. T. Sakuma, T. Aoyama and H. Takahashi: Solid State Ionics 7971 (1995)

27. S. Hull, D. A. Keen, D. S. Sivia and P. Berastegui: J. Solid State Chem. 165363 (2002)

28. S. Tahara, H. Ueno, K. Ohara, Y. Kawakita, S. Takeda, S. Kohara, and S. Ohno, J. Phys. Soc. Jpn 79 Suppl. A 133 (2010)

29. S.Ohno, A. C. Barnes, J. E. Enderby, J. Phys.: Condens. Matter 83785 (1996)

30. W. Biltz and W. Klemm, Z. Physik. Chem. 110318 (1924)

31. I. S. Yaffe and E. R. V. Artsdalen, J. Phys. Chem. 60 1125 (1956)

32. C. Tubandt and E. Lorentz: Z. Phys. Chem. 87513 (1914)

33. H. Arai, T. Koishi and S. Tamaki J. Phys. Soc. Jpn 68134 (1999)

34. S. Tamaki, T. Koishi and Y. Arai: High Temp. Mater. \& Process 1855 (1999)

35. M. Kobayashi, Physics of Solid State Ionics 2006 115

36. Y-W. Hu, I. D. Roistrick, and R. A. Fuggins, Electrochem. Soc. 1241240 (1977)

37. A. Wojakowska, E. Krzyzak Solid State Ionics 176 $2711(2005)$

38. G. Ciccotti, G. Jacucci, and I. R. McDonald, Phys. Rev. A 13426 (1976) 